Available online on 15.07.2018 at http://jddtonline.info
Open Access to Pharmaceutical and Medical Research
commercial use, provided the original work is properly cited

Open $\odot$ Access

Research Article

\title{
PHYTOCHEMICAL STANDARDIZATION AND ANTIOXIDANT POTENTIAL OF AYURVEDA FORMULATION DARVYADI RASKRIYA
}

\author{
Biresh Kumar Sarkar ${ }^{1}$, Ravi Kumar ${ }^{1}$, Vikas Kumar ${ }^{1}$, Reeta $^{1}$, Shashi Pal ${ }^{2}$, C. Murali Krishna ${ }^{3}$, S. C. Verma ${ }^{4}$, \\ Ravindra Singh ${ }^{5}$, Ramaiah Maddi ${ }^{6}$ \\ ${ }^{1}$ Central Ayurveda Research Institute for Respiratory Disorder, (CCRAS, Ministry of AYUSH, Govt. of India) Motibag Road, \\ Patiala, Punjab, India, 147001. \\ ${ }^{2}$ Manav Bharati University, Solan, HP, India. \\ 3 Regional Ayurveda Research Institute for Skin Disorders, (CCRAS, Ministry of AYUSH, Govt. of India), Vijayawada, India. \\ ${ }^{4}$ Pharmacopoeial Laboratory for Indian Medicine (PLIM) Ghaziabad, UP, India. \\ ${ }^{5}$ Central Council for Research in Ayurvedic Sciences (CCRAS Ministry of AYUSH, Govt. of India), New Delhi-110058 India. \\ ${ }^{6}$ Dept. of Pharmacognosy, Hindu College of Pharmacy, Amaravathi Road, Guntur 522002, A.P., India.
}

\begin{abstract}
The study represents phytochemical standardization and antioxidant potential of ayurveda formulation Darvyadi Raskriya. The study involves development of high-performance thin-layer chromatographic (HPTLC) method for analysis of formulation. The study utilizes analysis of glycyrrhizin in formulation which is the phytoconstituent of Glycyrrhiza glabra one of the component of formulation. The sample in ethanol was applied on aluminium TLC plates using Linomat 5 spray (CAMAG). Linear ascending development was performed in twin trough glass chamber saturated with mobile phase. The mobile phase consisted of ethyl acetatemethanol-formic acid $(10: 5: 1 \mathrm{v} / \mathrm{v} / \mathrm{v})$. The spectrodensitometric detection was performed at the wavelength of $254 \mathrm{~nm}$. The regression analysis was found to be linear with $\mathrm{r}^{2}=0.997$ in the concentration range $5-25 \mathrm{ppm}$. The antioxidant activity of formulation was also found to be significant as compared to control.
\end{abstract}

Keywords: Standardization, Glycyrrhiza glabra, Glycyrrhizin, HPTLC, Antioxidant.

Article Info: Received 03 June, 2018; Review Completed 12 July 2018; Accepted 13 July 2018; Available online 15 July 2018

Cite this article as:

Sarkar BK, Kumar R, Kumar V, Reeta, Pal S, Krishna CM, Verma SC, Singh R, Maddi R, Phytochemical standardization and antioxidant potential of Ayurveda formulation Darvyadi Raskriya, Journal of Drug Delivery and Therapeutics. 2018; 8(4):331-334 DOI: http://dx.doi.org/10.22270/jddt.v8i4.1806

*Address for Correspondence:

Biresh Kumar Sarkar, Central Ayurveda Research Institute for Respiratory Disorder, (CCRAS, Ministry of AYUSH, Govt. of India) Motibag Road, Patiala, Punjab, India, 147001.

\section{INTRODUCTION}

The standardization of drugs is very important aspect to ensure quality and integrity of a specific drug. The standardization also play vital role towards the quality concern of herbal drugs however the standardization of herbal drugs are difficult as compared to modern allopathic medicine due to the presence of large number of phytoconstituents. Recently many researchers emphasized need of herbal drug standardization for enhancing global acceptance of herbs and herbal formulation. The traditional as well as modern instrumental methods were used extensively for the standardization of natural drug in last two decades ${ }^{1-3}$. High Performance Thin Layer Chromatography (HPTLC) is one of the important instrumental methods used for this purpose. This method enables researchers to identify or quantify marker compounds in herbal formulation and play vital role in standardization of natural remedies. HPTLC is not only accurate and precise technique but it also having other advantages 
such as; cost effectiveness and selectivity ${ }^{4,5}$. HPTLC applied for the qualitative and quantitative estimation of herbs, fermentation mixtures, drugs obtained from animal sources and ayurveda formulation ${ }^{6}$.

Darvyadi Raskriya is an ayurveda formulation which is a prepared as juice or decoction till to become semisolid 7. Darvyadi Raskriya offer many therapeutic properties and used in the treatment of dry eye and infected eyes. It consisted of Berberis aristata, Trichosanthes dioica, Glycyrrhiza glabra, Nelumbo nucifera, Prunus puddum, Nelumbo nucifera and Azadirachta indica 8, 9. Glycyrrhiza glabra is one of the chief components of formulation; considering this aspect present study involves standardization of Darvyadi Raskriya using analytical study of chemical constituent of Glycyrrhiza glabra in formulation.

\section{MATERIALS}

The Darvyadi Raskriya was ordered and purchase from local market. CAMAG TLC system comprising of a Linomat-5 applicator and CAMAG TLC III scanner was used with stationary phase silica gel G60F254. The plates were developed in a CAMAG twin trough glass chamber by ascending method. The solvents and other reagent were of high purity grade.

\section{METHODS ${ }^{10}$}

\section{Preparation of standard solutions}

The standard solution was prepared by dissolving $10 \mathrm{mg}$ Glycyrrhizinate in $10 \mathrm{ml}$ methanol. The aliquots of varying concentration were prepared by further dilution i.e; $5,10,15,20$ and $25 \mu \mathrm{g} / \mathrm{ml}$.

\section{Chromatographic Conditions}

The chromatographic analysis was performed on $20 \mathrm{~cm}$ $\times 10 \mathrm{~cm}$ HPTLC silica gel G60F254 plates with fluorescent indicator. The sample and standard solutions were applied as bands using CAMAG Linomat automated spray equipped with a $100 \mu \mathrm{l}$ syringe, other settings were as follow:

$>$ Band length $6 \mathrm{~mm}$

$>$ Application rate $3 \mu \mathrm{l} / \mathrm{sec}$

$>$ Distance between bands $4 \mathrm{~mm}$

$>$ Distance from the plate side edge $7 \mathrm{~mm}$

$>$ Distance from the bottom of the plate $2 \mathrm{~cm}$.

\section{Calibration Curve}

Different concentration of standard solution was applied onto TLC plate to obtain linear relationship using calibration curve. The chromatograms were developed in specified chromatographic conditions. The plate was air dried followed by drying in hot air oven at $105^{\circ} \mathrm{C}$ for $5 \mathrm{~min}$. The spots were measure by linear scanning at 254 nm CAMAG TLC Scanner.

\section{Analysis of glycyrrhizin in formulation}

The Darvyadi Raskriya was taken in conical flask and extracted several times with ethanol then sonicated. The final extract of formulation was filtered through Whatman filter paper and filtrate was used for further analysis. The sample solution was run in identical chromatographic conditions and spot of biomarker identified as mentioned in figure $\mathbf{1}$.

\section{Method Validation}

Repeatability: Repeatability was carried out using the three replicates of same spot $1000 \mathrm{ng} / \mathrm{spot}$.

Intermediate precision: The intra-day and inter-day variations for determination of standard were carried out at different concentration levels.

Recovery Studies: Recovery study was performed by spiking samples with standard at three different concentration level. The recovery study was performed in triplicate; the study ensures recovery of drugs at different levels of formulations.

\section{Antioxidant Activity (DPPH Radical Scavenging Assay)}

The antioxidant property of plant was measured using DPPH radical scavenging method ${ }^{11}$. The antioxidant activity was compared with ascorbic acid. The antioxidant activity of formulation was performed in varying concentration. $1.5 \mathrm{ml}$ of $0.1 \mathrm{mM}$ DPPH solution was mixed with $1.5 \mathrm{ml}$ of various concentrations of formulation. The mixture was shaken vigorously and incubated at room temperature for $30 \mathrm{~min}$ in the dark. The reduction of the DPPH free radical was measured by reading the absorbance at 517 on spectrophotometer. The solution without any sample along with DPPH and methanol was used as control. Inhibition of DPPH free radical in percentage was calculated by the following formula:

$$
\text { Inhibition }(\%)=\left[\left(\mathrm{A}_{\text {control }}-\mathrm{A}_{\text {test }}\right) / \mathrm{A}_{\text {control }}\right] \times 100
$$

Where; $\mathrm{A}_{\text {control }}$ is the absorbance of the control (LAscorbic acid)

$A_{\text {test }}$ is the absorbance of reaction mixture sample (in the presence of sample).

\section{RESULT AND DISCUSSION}

\section{Mobile Phase Development}

The solvent system composed of ethyl acetatemethanol-formic acid (10:5:1 v/v/v) was used for estimation of glycyrrhizin. Separate chromatogram was observed with $R_{f}$ value $0.35 \pm 0.03$ as mentioned in figure $2 \& 3$.

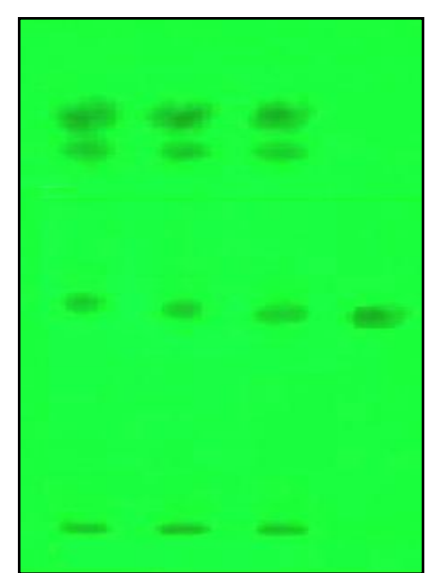

Figure 1: TLC profile of Test solutions and Standard solutions 


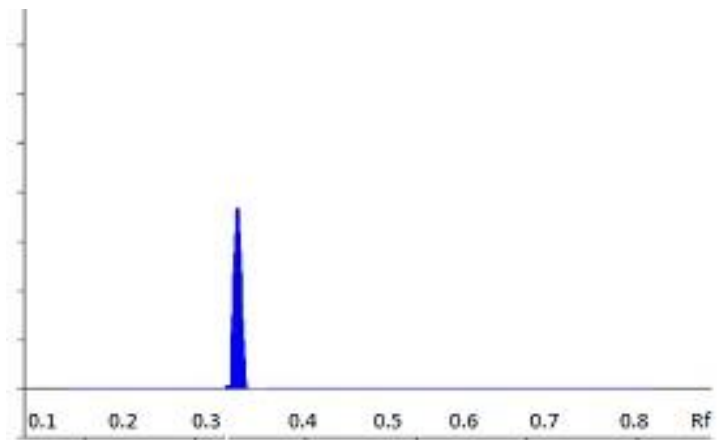

Figure 2: HPTLC chromatogram of standard.

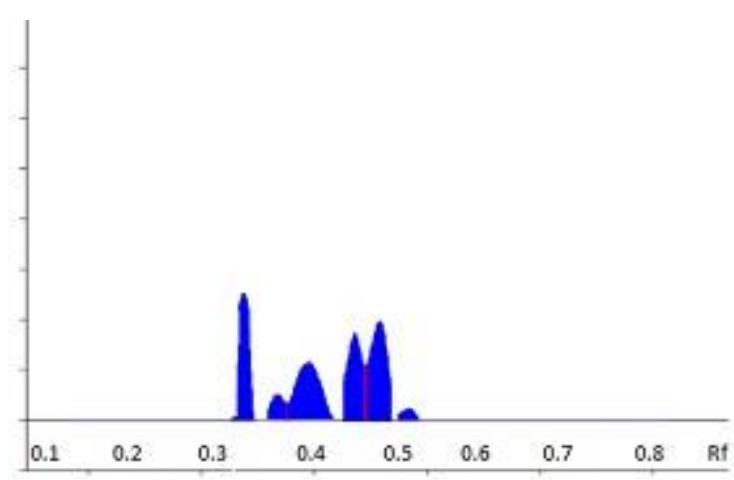

Figure 3: Chromatogram of sample.

\section{Linearity}

Linear regression data showed good linear relationship with in specified concentration range. The correlation coefficient $r^{2}$ was found to be $r^{2}=0.997$ as shown in figure 4 .

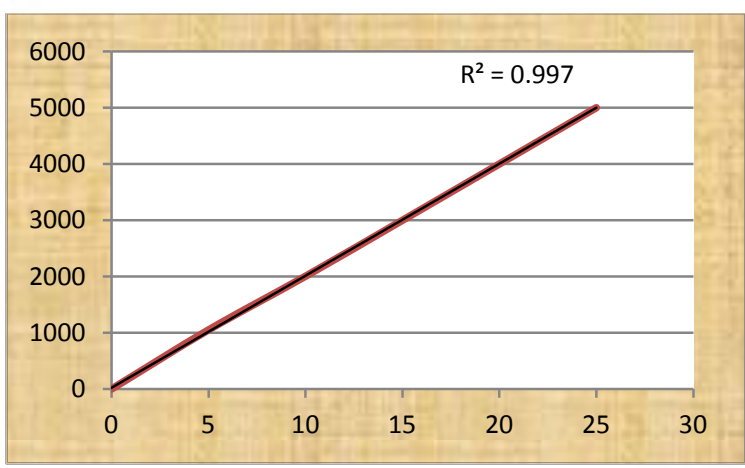

Figure 4: Calibration graph shows linear relationship between concentration and peak area.

\section{Validation parameters}

Repeatability showed very low \% RSD of peak area of active component of formulation. Intermediate precision and recovery studies were also found to be within range as mentioned in table 1.

\section{DPPH Radical Scavenging Assay}

The selected ayurveda formulation was also evaluated for its antioxidant potential using DPPH radical scavenging activity. The result of study observed dose dependent response for ayurveda formulation as shown in figure 5. Potent antioxidant activity was observed with high concentration of formulation extract. The antioxidant potential of formulation attributed to its phytoconstituents $^{12}$.

Table 1: The results of validation parameters

\begin{tabular}{|c|c|c|}
\hline \multicolumn{3}{|c|}{ Repeatability study } \\
\hline Sample applied ng & \multicolumn{2}{|c|}{ \% RSD } \\
\hline 1000 & \multicolumn{2}{|c|}{0.055} \\
\hline 1000 & \multicolumn{2}{|c|}{0.058} \\
\hline 1000 & \multicolumn{2}{|c|}{053} \\
\hline \multicolumn{3}{|c|}{ Intermediate precision } \\
\hline Sample applied ng & $\begin{array}{c}\text { Intraday } \\
\text { \% RSD }\end{array}$ & $\begin{array}{c}\text { Interday } \\
\text { \% RSD }\end{array}$ \\
\hline 200 & 1.96 & 1.6 \\
\hline 400 & 1.98 & 1.89 \\
\hline 1000 & 1.95 & 1.92 \\
\hline \multicolumn{3}{|c|}{ Recovery studies } \\
\hline \%mount added & \multicolumn{2}{c|}{0.169} \\
\hline 20 & 0.298 \\
\hline 40 & 0.275 \\
\hline
\end{tabular}

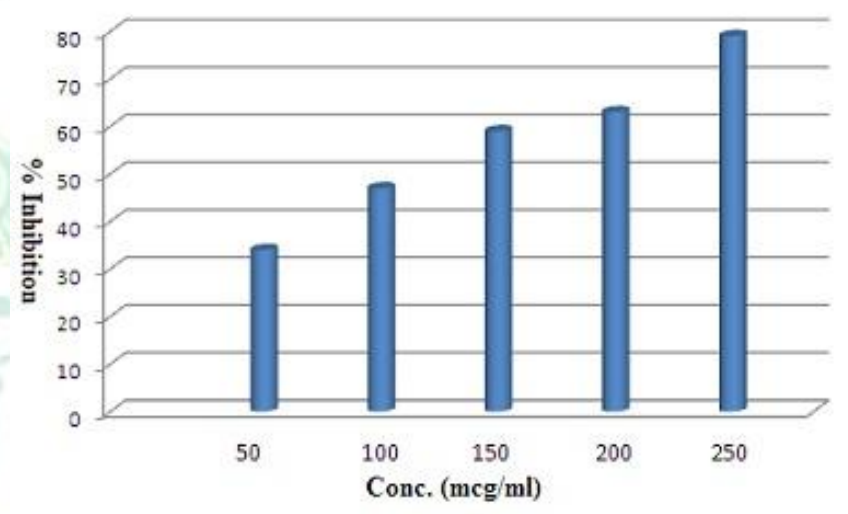

Figure 5: Antioxidant activity of sample

\section{CONCLUSION}

The present study involves phytochemical standardization and antioxidant potential of ayurveda formulation Darvyadi Raskriya. The standardization of formulation was performed using high-performance thin-layer chromatographic (HPTLC) method using glycyrrhizin (Glycyrrhiza glabra) as marker which is one of the important components of formulation. The linear relationship between concentration and area was observed with $\mathrm{r}^{2}=0.997$ for regression analysis. The validation parameters for HPTLC method were also found within range and identical chromatogram was detected in formulation with $R_{f} 0.35 \pm 0.03$. The formulation also evaluated for antioxidant potential using DPPH assay. The antioxidant activity of formulation was also found to be significant as compared to control. The results of study may be used as trail for the further development of ayurveda formulation. 


\section{REFERENCES}

1. Iqbal Ahemad, Farrukh Aqil, Mohammad Owais. (Ed), Modern Phytomedicine, wiley-VCH Verlag Gmbh \& Co. KGa A. Weinheim, 2006.

2. Swapnil G, Patil. Standard Tools for Evaluation of Herbal Drugs: an Overview, The Pharma Innovation - Journal. 2013; 2(9):60.

3. SagarBhanu, P.S., Zafar R. \&Panwar R., Herbal drug standardization. The Indian Pharmacist, $2005 ; 4$ (35): 19-22.

4. Ansari, S.H. "Standardization of the crude drugs", Essentials of Pharmacognosy, I ${ }^{\text {st }}$ edition, 2005; 14:581.

5. Faisal MS, Naz Z, Shakeel F, Ahmed S, Kohli K, Khar RK. A new TLC densitometric method for stability assessment of modafinil. Chem Analityczna 2009; 54:77-88.

6. Ali B, Mujeeb M, Aeri V, Mir SR, Ahmad S, Siddique NA, et al. High-performance thin layer chromatographic quantification of bioactive psoralen and daidzein in leaves of Ficus carica L. Nat Prod Res 2011; 25:1666-1670.
7. Dr. Smt. Shailaja Srivastava, Sharangdhar Samhita, Madhyam Khanda, Chaukhamba oriantalia, Varanasi, 2009; 8(1):208- 209.

8. Prof. K. C Chunekar, reprint edition Bhav Prakash Nighantu of Shri Bhav Mishra, chaukhamba Bharati Academy, 2013; 1(202): 115 .

9. Prof. K. C Chunekar, reprint edition Bhav Prakash Nighantu of Shri Bhav Mishra, chaukhamba Bharati Academy, 2013; 2(131):255.

10. Bernard Fried, Joseph Sherma, Practical Thinlayer Chromatography: A Multidisciplinary Approach, CRC Press, 1996; 233- 234.

11. Hsu CY., et al. Antioxidant activity of extract from Polygonum cuspidatum. Biol Res 2007; 40:13-21.

12. Koleva II, Van Beek TA, Linssen JPH, De Groot A, Evstatieva L.N. Screening of plant extracts for antioxidant activity: a comparative study on three testing methods. Phytochem Anal 2002; 13:8-17. 